\title{
The effect of musical fit on consumers' memory
}

\begin{abstract}
This study investigated the impact of musical 'fit' on memory for items. Participants were asked to recall 20 items they had seen while listening to either rock music or classical music. Some of the 20 items were associated with either the rebellious stereotype of rock music or the affluent stereotype of classical music. More 'rock items' than 'classical items' were recalled when rock music was played, although a similar number of 'classical items' and 'rock items' were recalled when classical music was played. When rock music was played, participants recalled 'rock items' earlier than 'classical items' and the reverse was found when classical music was played. This suggests that musical 'fit' operates by raising the salience of items.
\end{abstract}

Keyword: Consumers; Memory; Music 